\title{
O LOCAL E O TRANSNACIONAL NAS NEGOCIAÇÕES PELA INCLUSÃO DA CATEGORIA “AFRODESCENDENTE” NO CENSO ARGENTINO".
}

\author{
Laura Cecilia López \\ Doutoranda do Programa de Pós-Graduação em Antropologia Social da \\ Universidade Federal do Rio Grande do Sul (UFRGS).
}

\begin{abstract}
RESUMO
Este trabalho analisa um episódio recente de negociações e disputas entre diferentes atores (ativistas afroargentinos, agentes do Estado e organismos de financiamento) pela inclusão de uma quantificação da população afrodescendente na Argentina no próximo censo nacional 2010. Examino como fluxos e agentes globais revitalizam a discussão sobre o "étnico", o "racial" e o "nacional", reordenando noções e classificações das minorias no plano local, particularmente através dos modos de contabilizar e categorizar essas coletividades nas estatísticas oficiais.

Palavras-Chave: Afroargentinos. Censos. Transnacionalização. Classificações Étnico-Raciais.
\end{abstract}

\begin{abstract}
This study analyzes recent negotiations and disputes among agents (Africanargentine activist, local government employees and global agents) involved in the inclusion of a number of African descendants in the 2010 national census. This phenomenon is interpreted in the context of the last decade transnationalization of social movements. I examine how transnational fluxes and agents revive the debate about ethnical, racial and national issues, reorganizing concepts and racial classifications, particularly throw the official ways of accountability and categorization of these collectivities.

Key Words: African-Argentineans. Census. Transnationalization. Ethnic-racial classifications.
\end{abstract}

\section{Introdução}

No presente trabalho analiso um episódio recente de negociações e disputas entre diferentes atores (a saber, ativistas afroargentinos, agentes do Estado local e organismos internacionais de financiamento) pela inclusão de uma quantificação da população afrodescendente na Argentina no censo nacional. Examino como fluxos e agentes globais revitalizam a discussão

\footnotetext{
${ }^{1} \mathrm{O}$ trabalho é parte da análise feita em: López, Laura. "¿Hay alguna persona en este Hogar que sea Afrodescendiente?” Negociações e disputas políticas em torno das classificações étnicas na Argentina. Dissertação de Mestrado. Porto Alegre: PPGAS/UFRGS, 2005.
} 
sobre o "étnico", o "racial” e o "nacional”, reordenando noções e classificações das minorias no plano local, particularmente através dos modos de contabilizar e categorizar essas coletividades nas estatísticas oficiais.

A questão da quantificação oficial dos afrodescendentes vem sendo uma exigência de atores globais sobre os Estados Nação na América Latina visando avaliar a situação sócio-econômica dessa população e, em base nesses resultados, planejar o financiamento de projetos de desenvolvimento para essas comunidades. Ditas exigências ganharam nova força a partir da Conferência Mundial das Nações Unidas contra o Racismo, a Discriminação Racial a Xenofobia e outras formas correlatas de Intolerância, celebrada em Durban, África do Sul, no ano 2001. A Declaração Final ${ }^{2}$, assinada pelos Estados participantes, recomenda aos países da América Latina contar com dados oficiais sobre os afrodescendentes, para formular e avaliar políticas reparatórias e de inclusão social destinadas a essa população em relação à dívida resultante do processo escravista.

Essas recomendações e exigências internacionais provocaram diversidade de situações nos planos locais. No caso da Argentina, não existiam perguntas no censo sobre raça / cor / etnicidade, só no ano 2001 foi realizada uma pergunta de auto-identificação de povos indígenas. No ano 2003 começaram as negociações entre agências internacionais, funcionários do Instituto Nacional de Estadísticas y Censos (INDEC) e ativistas afro para a formulação de uma pergunta a ser incluída no censo 2010 que dê conta dos descendentes de africanos. A elaboração da pergunta - que esteve a cargo de um grupo de ativistas, duas deles contratadas pelo INDEC e o Banco Mundial (BM) como consultores, e que forma parte do questionário que está sendo testado numa Prova Piloto financiada pelo BM durante o ano 2005 - ocasionou debates acerca de que categoria usar para dar conta dessa população.

Relaciono esse fenômeno com a constituição de um espaço transnacional dos movimentos negros na América Latina (GARCIA, 2001). Com o termo "transnacionalização" refiro a práticas e processos que vinculam atores sociais através de fronteiras nacionais (SMITH; GUARNIZO, 1998). Nesse caso, referimos a conformação de agenciamentos políticos que perpassam fronteiras através de redes internacionais de organizações negras, assim como a inclusão de temáticas relativas à população negra latino-americana nas agendas de "governabilidade global" de organizações internacionais e corporações multinacionais (WADE, 19997).

Por um lado, na última década, os movimentos negros (entre outros movimentos étnicos) demandam por reformas no campo dos direitos,

\footnotetext{
${ }^{2}$ A Declaração foi consultada no site da ONU: www.un.org/spanish/CMCR
} 
políticas afirmativas e autonomia cultural (WADE, 19997). Em alguns casos, os governos adotaram políticas - incluídas reformas constitucionais, que reconhecem a composição multi-étnica de suas nações e acordam certos direitos especiais para esses grupos desfavorecidos desde o domínio colonial, reformulando a concepção de cidadania homogênea do nacionalismo republicano clássico que propõe "direitos iguais a todos". Os novos direitos implicam o reconhecimento da dívida histórica do Estado para com esses grupos: seja como proprietários originais de terras, como sujeitos da escravidão, como vítimas do racismo (ARRUTI, 2000).

Por outro lado, ditos fenômenos de escala nacional devem ser compreendidos no contexto de mudanças acontecidas desde os anos 1970 nas responsabilidades internacionais e na proliferação de atores não-governamentais com um papel cada vez mais importante na cena mundial. Como resultado da descolonização dos países do Terceiro Mundo, se criaram novos setores de interesse e alianças de Estados nacionais opostos ao colonialismo e desenvolvendo uma retórica anti-colonial persistente nas Nações Unidas. As organizações não-governamentais (ONGs), as organizações inter-governamentais (como o Banco Mundial) e as corporações multinacionais estão cada vez mais inseridas nas lutas étnicas. Cabe esclarecer que a transformação nas normas internacionais deu à categoria de "povos indígenas" estatuto consultivo de Nações Unidas no ano 1992, e a de "afrodescendente", a partir da Conferência de Durban em 2001. Assim, a questão do reconhecimento das nações como multi-étnicas e as políticas reparatórias para com minorias historicamente desfavorecidas passam a constituir "valores globais" no sentido dos Estados serem "avaliados" a nível internacional no seu cumprimento dessas disposições (MATO, 1993).

É importante considerar a complexidade das reconfigurações de movimentos étnicos decorrentes destes processos de transnacionalização e o conflito de representações e interesses que produzem no plano nacional, já que implicam processos, chamados por alguns autores de "transnacionalização a partir de baixo". Quer dizer, a conformação de uma "comunidade global" através da qual os povos historicamente oprimidos pelos Estados nacionais inscrevem suas identidades tornando-as visíveis na ordem mundial, se associam através das fronteiras nacionais e oferecem resistência no plano local. Esses movimentos baseiam suas ações na possibilidade de que a natureza do Estado (coercitiva) possa ser acomodada à luz de demandas por mudanças de uma força normativa baseada na existência de uma comunidade política global (WILMER, 1993).

Porém, a força "global" que sustenta a ação das organizações da sociedade civil na busca de suportes nacionais e internacionais para seus pleitos não 
pode ser circunscrita tão só a suas próprias iniciativas. Essa transnacionalização "desde baixo" é também, pelo menos em parte, uma resposta a outros processos que podem ser considerados parte de uma transnacionalização "a partir de cima" que geralmente envolve as atividades de elites poderosas, que controlam corporações, médios e finanças multinacionais (SMITH; GUARNIZO, 1998). No nível local, os governos e os atores multilaterais específicos (Nações Unidas, Fundo Monetário Internacional, Banco Mundial, etc.) constróem uma "nova ordem mundial" para regular os fluxos transnacionais de capital, comércio, pessoas e cultura(PANTALEÓN, 2002).

Examino estes processos para interpretar as reformulações dos censos, já que constituem uma problemática contemporânea que está inserida em espaços transnacionais tanto de reivindicação de movimentos sociais quanto de responsabilidades dos Estados nacionais. A sua vez, incorporo uma dimensão histórica-política dessas categorias nas estatísticas oficiais, reconstituída a partir de uma revisão de literatura e fontes.

\section{Censos e transnacionalização.}

Os censos têm se transformado nos últimos anos em interesse das ciências sociais, seja em sua dimensão histórica, por seu papel na conformação das identidades nacionais e de sua homogeneização como nação; seja pelos embates atuais, apontando tanto a identidades e estratégias de minorias, quanto aos desafios para a elaboração de políticas públicas de reconhecimento e de inclusão social que os recenseamentos por raça e etnicidade estão tentando basear (PANTALEÓN, 2002).

A desconstrução contemporânea desse fenômeno implica levar em conta que a formulação das perguntas e categorias dos censos está embebida em debates políticos. O censo faz muito mais do que simplesmente refletir uma realidade social, ele joga um papel chave na construção dessa realidade. É um dos mecanismos de enquadramento das populações que o poder público utiliza. Através dos censos os Estados classificam as populações nacionais em categorias separadas e hierarquicamente relacionadas através de mecanismos arbitrários e de arbitragem. São classificações exteriores à população considerada e resultante das relações de força entre os diferentes grupos que integram o Estado (KERTZER, 1999). A sua vez, os censos dão-nos pistas sobre o que buscam e entendem os agentes governamentais como os "problemas" da sociedade nacional.

Apesar das desconstruções de cientistas sociais, até a atualidade continuase apelando, sobretudo no conhecimento produzido por estadistas, ao que Labbé (apud KERTZER, 1999), chama de "realismo estatístico", quer dizer, a uma lógica quantitativa baseada na idéia de que o objeto a ser enumerado 
"existe previamente e por fora das estatísticas". Esse ponto é central para entender conflitos ocasionados tanto nos enquadramentos das populações que fazem os Estados, informados por ideologias nacionais, quanto nos que realizam os atores globais, guiados também por ideologias dominantes num plano transnacional.

Em linhas gerais, as disputas atuais pelas categorias censitárias por raça e etnicidade formam parte de um espaço político transnacional, com pressões dos atores globais nas decisões dos organismos estatísticos nacionais em relação a questões de combate à discriminação e políticas públicas de "discriminação positiva”.

No caso do Banco Mundial (BM) e do Banco Inter-americano de Desenvolvimento (BID), a partir do ano 1995, suas políticas e programas foram orientados para o "alívio à pobreza" presente nos países da América Latina. Nos discursos aparece uma relação direta entre pobreza e raça / origem étnica. Junto com os povos indígenas, as comunidades negras son consideradas como "grupos vulneráveis", partindo da idéia de que os negros e os indígenas são os "mais pobres dos pobres", motivando novas leituras sobre "pobreza" e sobre "problema social" que privilegiam as variáveis étnicas e raciais por sobre as de classe para compreender a exclusão social.

Expressa um documento do BM do ano 1995 que essa instituição juntou-se com o BID e a Comissão Econômica para a América Latina e o Caribe (CEPAL) para elaborar um programa regional de assistência técnica para melhorar as enquetes domiciliárias e obter dados mais precisos sobre pobreza. Mas esse trabalho sobre as estratégias de redução à pobreza levaram à "necessidade de melhorar as ferramentas de coleta de dados para que reflitam em forma mais exata os Estados afetados pela pobreza de grupos historicamente excluídos na América Latina e o Caribe" (ou seja, negros e índios).

O BID impulsionou no ano 1996 a formação da rede internacional de organizações negras Afroamérica XXI visando "analisar e propor soluções viáveis frente à situação de pobreza, desigualdade e discriminação de que ainda, lamentavelmente, são objeto os membros de nossas comunidades afrolatinoamericanas"3. Na Declaração que dá início à rede, as comunidades negras são chamadas a apelar aos governos, organismos multilaterais e agências de cooperação para o desenvolvimento, para que ajustem suas políticas sociais e econômicas tomando como referência as recomendações propostas pela rede. Fundamentalmente, exigindo ações "que levem em conta os níveis

\footnotetext{
${ }^{3}$ Nos anos 90 foram criadas também a Rede Continental de Organizações Afro (criada no Uruguai em 1994), e a Aliança Global Latino-caribenha (que surge em Nova York em 1999 como confluência das outras duas redes).
} 
de vulnerabilidade e risco em que se encontram a massa dos membros de nossa comunidade". Esta Declaração foi assinada no quadro do Foro "Alívio à pobreza às minorias étnicas na América Latina" celebrado em Washington DC em novembro de 1996, do qual participaram duas lideranças afroargentinas ${ }^{4}$.

No ano 2000 se formou o Programa sobre Raça do Diálogo Interamericano e a Consulta Interagencial sobre Raça na América Latina (IAC) sendo um grupo consultivo de instituições de desenvolvimento internacional, conformado pelo BM, o BID e as Fundações Inter-americana, Ford e Rockefeller. Seu objetivo é instalar a temática de "raça" no cenário transnacional, assim como nos planos nacionais abordando questões de discriminação racial, exclusão social e outros problemas das populações afrodescendentes da América Latina, apontando a três classes de público: as instituições membros, os governos nacionais e os grupos afrodescendentes. . Num documento do IAC de 2003, é ressaltada a importância das políticas de ação afirmativa para combater os padrões de exclusão social e desigualdade estrutural, e o Brasil é tomado como exemplo de visibilidade desse tipo de políticas (tanto na mídia quanto nos projetos de lei estaduais e federais), ponderando a repercussão das políticas de ação afirmativa num país com numerosa população negra e o impacto que pode causar no resto da América Latina para implementar a temática racial como central para resolver a desigualdade social ${ }^{5}$.

Tal chamamento é interessante porque na apresentação do Programa e da Consulta, raça está diretamente associado a população negra, não fazem alusão a indígenas. Assim, aparentemente, a questão não refere a indígenas, mas também não abrange igualmente a pobreza "em geral”, redirecionando as atuações do Estado-nação a um determinado aspecto como isolado dos demais.

Na mesma época começam uma série de reuniões denominadas "Todos Contamos”, organizadas pelo BM e o BID para os órgãos estatísticos dos governos da América Latina com a participação das ONGs dos movimentos sociais de cada país, que têm como objetivo dar ferramentas analíticas para o trabalho sobre a pobreza. O primeiro encontro foi no ano 2000 na Colômbia, no que participaram pela Argentina um funcionário do INDEC e um representante indígena. Naquele momento o tema em questão era a pergunta de auto-identificação para os indígenas no censo de 2001, relacionada com

\footnotetext{
${ }^{4} \mathrm{O}$ impacto na Argentina da criação da rede foi importante já que dois de seus coordenadores viajaram a Buenos Aires em 1996, entraram em contato com as organizações negras existentes naquele momento e impulsionaram a formação de novas organizações.

${ }^{5}$ Informação extraída do site www.iadialog.org/iac.
} 
o reconhecimento de direitos dos povos indígenas na Constituição de 1994 e a vigência do Convênio 169 da Organização Internacional do Trabalho $(\mathrm{OIT})^{6}$.

No segundo encontro, denominado "Censo Nacional e Inclusão Social”, celebrado no Peru em 2002, participaram o funcionário do INDEC, um representante indígena um representante afro, já que começava-se falar da inclusão no censo da pergunta sobre afrodescendência, no contexto posterior à Conferência de Durban de 2001.

Assim, no jogo político entre agências internacionais e Estados nacionais, as agências propõem-se a financiar projetos de eqüidade social desde que os Estados nacionais se co-responsabilizem por "diagnósticos” (censitários) que indiquem os problemas sociais aos quais dirigirem financiamentos.

Segundo mostram os documentos, nessas reuniões debateram-se temas tais como; quais os conceitos e metodologias que dessem conta da origem étnica; quais variáveis para acessar ao nível sócio-econômico de grupos étnicos e/ou raciais e qual a participação dos grupos comunitários no desenho e aplicação das metodologias. A idéia é "contar com dados demográficos e sócio-econômicos mais confiáveis para desenhar operações de inversão mais eficazes e proporcionar serviços de desenvolvimento a grupos raciais e étnicos e outros grupos vulneráveis". O documento geral está acompanhado de outros que relatam as experiências em alguns países como o Brasil, Equador e Guatemala, colocando problemas específicos na aplicação de algum tipo de contabilidade dos afrodescendentes e indígenas, sobretudo em relação às categorias a aplicar.

Todas essas alianças, diretrizes e recomendações foram melhor articuladas na Conferência de Durban de 2001. Segundo a Declaração Final, os dados dos censos ofereceriam às instâncias normativas um instrumento para formular e avaliar políticas de Estado.

Chamo a atenção para duas questões inter-relacionadas. Por um lado, nos documentos percebi uma relação direta entre pobreza e etnicidade / raça, baseada num vínculo direto entre o passado colonial e o presente, questões que englobam a índios enegros como "grupos vulneráveis", vistos como "os mais pobres dos pobres”, sem levar em conta a historicidade desses atores nos

\footnotetext{
${ }^{6}$ A pergunta incluida no censo 2001 foi: “¿Existe en este hogar alguna persona que se reconozca descendiente o perteneciente a un pueblo indígena?". Se a pessoa respondia afirmativamente, a segunda parte era: “ $i A$ qué pueblo?". Figuravam 18 opções de povos e outra que referia a “ignorado”. Dita pergunta foi considerada como "de captação", para depois fazer uma enquete complementar, que foi realizada em 2004 em alguns dos lares para aprofundar a informação. O questionário incluiu perguntas sobre os ancestrais, línguas indígenas e outros temas como educação, saúde, trabalho, condições de moradia e problemas específicos desses grupos. Informação extraída do site www.indec.mecon.gov.ar.
} 
contextos nacionais, ou seja, passando ao Estado-nação, através dos censos, a prerrogativa de escolher suas prioridades à despeito dos pleiteantes e dos movimentos historicamente produzidos.

Por outro lado, a necessidade de "refletir de maneira mais exata os Estados afetados pela pobreza de grupos historicamente excluídos (índios e negros)" para desenhar operações de inversão, leva à questão do "realismo estatístico", fazendo a operação de redução de categorias culturais (já que a inclusão no censo seria por auto-adscrição e não por definição externa) a critérios objetivos.

Qual é, então, a construção da afrodescendência nestes discursos?

Retomo as idéias de João Pacheco de Oliveira (2000), em sua análise das diretrizes do BM à luz dos problemas da política indigenista brasileira e das lutas e mobilizações dos indígenas no Brasil. $O$ autor afirma que o procedimento classificatório apontado por ditas diretrizes tenta aplicar aos fenômenos socioculturais o mesmo tipo de definição empregado para os fenômenos naturais, trazendo graves conseqüências ao conceituar os grupos como unidades discretas que podem ser descritas através da presença/ausência de características genéricas. Tal equívoco alimenta os estereótipos e preconceitos que se encontram no senso comum e nos discursos cotidianos.

Dentro dessa lógica classificatória agrega-se a noção de "vulnerabilidade" (vinculada a "autenticidade"), critério que também não é susceptível de uma aplicação direta. Embora existam grupos indígenas (e negros) que entrem nesses parâmetros, o que acontece com os que não entram? E, de outra parte, quem são os sujeitos autorizados para manejar as classificações? $\mathrm{O}$ autor fala que para as populações que tem contato antigo com o branco e que incorporaram muitas de suas instituições, as tentativas de aplicação do critério acabariam abrindo espaço e dando foros de legitimidade para um debate sobre a pretensa autenticidade daquelas coletividades, idéias tão ao gosto das instâncias de poder e que delegam ao Estado-nação e seus agentes a prerrogativa de escolha dos "merecedores" de atenção.

Ressalto, então, o poder das classificações e o fato do Estado-nação deter uma ferramenta que é ambígua - ao mesmo tempo que identifica os que deve "promover", toma para si a possibilidade de excluir outros sob o argumento censitário que ele próprio maneja e do qual extrai sua legitimidade.

Porém, a luta por inserir categorizações no censo não é um episódio só recente, mas revelador de uma luta pelas classificações, e por intervir em um funcionamento aparentemente burocrático, mas que vem se demonstrando uma das mais duradouras formas de escolher, excluir e imaginar um "problema social”, os "nacionais" e uma nação. 
No caso dos negros na Argentina, o processo de descaracterização étnica dessa população ao longo do século XX, faz com que não entrem no critério de "autenticidade" como parte das origens da nação, sendo difícil, em alguns casos (obviamente dentro dessa lógica) mostrar que possuem uma cultura própria que os identifique como grupo diferenciado. Aliás, a mobilidade social ascendente e a "integração à sociedade branca" de setores desta população seria, nos termos técnicos e abrangentes, uma demonstração de que seria errado presumir-se o critério de "vulnerabilidade" para tais grupos.

Isto, somado à crise atual da Argentina, que coloca como "vulneráveis" a grupos "não-etnicizados” (que não entram nas categorias nem de 'índio' nem de 'negro') torna mais complexo o problema em relação sobre quem "precisa mais" de programas de desenvolvimento. Ou seja, desencadeia e põe em circulação um embate sobre quem são os mais pobres entre os pobres e o poder de nomeá-los como "merecedores".

\section{As classificações dos negros na Argentina em um perspectiva histórica}

Nesse tópico, incorporo uma dimensão histórica-política das categorias étnicas-raciais nas estatísticas oficiais para aprofundar a compreensão da localidade dos processo de reformulação do censo na Argentina.

$\mathrm{Na}$ consolidação dos Estados modernos, as elites foram categorizando a população, criando fronteiras através de identidades preexistentes. James Scott (apud Kertzer, 2002) refere a esse fato como um processo pelo qual o Estado "fez legível" a sociedade através de uma série de tipificações. Os construtores dos Estados não somente descreveram, observaram e mapearam, mas também modelaram o "povo". A decisão de enumerar e qualificar por categorias criava a questão de quais indivíduos incluir entre os nacionais, delimitando quem é cidadão nacional e quem não é, e como são as tipologias úteis para categorizá-los.

A sua vez, o projeto de dividir a população em categorias de identidade coletiva separáveis, sendo o produto da ideologia dos Estados coloniais e modernos, cruzou-se com a divisão da população em categorias raciais. Assim, as ideologias raciais do século XIX informaram a contagem e os marcadores dos censos e adequaram as Nações latino-americanas a um modelo de Estado-nação moderno, civilizado e pretensamente branco. Este ideário norteou a fabricação da nação Argentina como irei mostrar a seguir.

A construção dominante de uma "branquitude" até a atualidade (particularmente em Buenos Aires) a partir de macro-processos de invisibilização dos negros da história e cultura nacional foi materializada, entre outros mecanismos, através de operações censitárias. A modernização estatística, baseada no princípio liberal de igualdade perante a lei, apresentava contradições já 
que, se bem explicitava a intenção de rejeitar as categorias que remetiam ao passado colonial, tinha implícita a hierarquia das raças que supostamente combatia. $O$ projeto político de homogeneização da população privilegiava como elemento formador ao segmento branco, despreciando a negros e indígenas.

George Reid Andrews (1989) analisa o que foi chamado por muitos pensadores de "enigma do desaparecimento" dos negros na Argentina entre fins do século XIX e princípios do XX, tanto fisicamente quanto nas páginas da história nacional. A idéia que coloca o autor é de que a população negra foi invisibilizada a partir de mecanismos do Estado, encontrando os pontos chaves para compreender esse processo na ideologia do "branqueamento".

Tal operação foi reafirmada pelo desaparecimento dos registros oficiais relativos à ascendência africana através da utilização do rótulo "população desconhecida”, que subestimava o número de afroargentinos ao poder contemplar pessoas negras sem especificar a cor. Ou também o uso da categoria "trigueño" (da cor do trigo), que não implica diretamente ascendência africana. Esse rótulo racial foi comum no alistamento no exército. É uma categoria intermediária, sendo provável que o termo tivesse sido usado pelos descendentes de escravos para "fugir" da categoria mulato, que evocava um ancestral africano.

Através de sua "hipótese dos traslados estatísticos" o autor afirma que as fontes oficiais possibilitaram um branqueamento em duas dimensões: forçava a auto-identificação dos negros como 'trigueños' para escapar ao preconceito de raça; e manejava a categoria, através do tratamento estatístico da população trigueña à categoria branco.

A "mistura de raças", segundo o autor, estava se dando de maneira significativa através dos matrimônios inter-raciais, junto com o uso de uma terminologia racial ambígua, produzindo como resultado um número importante de "pardos" e "morenos" que foram contados como "brancos" nos registros demográficos oficiais. A sua outra face foi a de converter os nascidos na Argentina, que potencialmente eram vistos como criollos por uma elite colonial, em "brancos" desse emergente Estado-nação. Ou seja, assim como o censo criava nuanças a classificação racial, também forçava um englobamento que expressasse sua composição de uma maioria branca.

Desse modo, a hipótese de Reid Andrews é que os determinantes mais importantes do declínio numérico da população negra no período 1838-87, não foram o descenso nas taxas de natalidade nem as altas de mortalidade, como explicaram muitos pensadores (embora elas tenham contribuído), mas sim a passagem estatística de grande segmento da população afroargentina da categoria racial parda/morena à branca. 
Hernán Otero (1997-1998) tem retomado a "hipótese dos traslados estatísticos" de Reid Andrews, mas critica a idéia de que as categorias refletissem (ou não) "exatamente" a realidade racial, assumindo (contrariamente a Reid Andrews) que a "raça" não é um dado perceptivel desde fora, distinguindo "objetivamente” aos indivíduos, e sim uma construção social de caráter dinâmico.

A partir dos censos nacionais de população do período 1869-1914, Otero refere ao papel desempenhado pelo sistema estatístico nacional no duplo processo de conformação da Argentina como Estado e como Nação durante o século XIX, focalizando os instrumentos utilizados pelo primeiro para o desenvolvimento de uma tarefa que fazia-se mais imperiosa com o vertiginoso crescimento econômico e a chegada massiva de imigrantes europeus que desfazem os traços estabelecidos no regime sócio-demográfico colonial.

Vinculado com a transformação na percepção da sociedade operada com a irrupção do liberalismo e do princípio de igualdade ante a lei plasmada na Constituição Nacional, o autor aponta dois efeitos simbólicos produzidos pelos censos nacionais na geração de um discurso político-científico oficial sobre o processo sócio-demográfico argentino: a homogeneização da massa populacional heterogênea e a construção de uma determinada imagem da nação. Em ambos casos, os censos de população não foram um instrumento passivo ou simplesmente descritivo de medição, já que mediante a definição e seleção de categorias de análise contribuíram a criar uma imagem da nação que resultou, em parte, autônoma do processo histórico.

O efeito homogeneizador dos censos contribuiu a uniformizar no discurso a grupos heterogêneos de população estrangeira mediante a adscrição externa de identidades nacionais, já que bloqueava formas alternativas de auto-identificação dos indivíduos. Ou seja, uniformizou a variada gama de população nativa graças a uma série de operações conceituais e jurídico-políticas que: 1) negavam o caráter de nações às populações indígenas (cujo reconhecimento contrariava as pretensões territoriais hegemônicas do Estado); 2) suprimiam (de maneira progressista e comum a outros países latino-americanos) as categorias organicistas de origem colonial como a "raça" e, 3) promoviam a identificação igualitária mediante a jus solis ${ }^{7}$ das distintas gerações de imigrantes nascidas no país. Em outras palavras, englobando a jus sanguinis pela jus solis.

${ }^{7} \mathrm{O}$ jus solis determina que a nacionalidade de um indivíduo é a do território em que nasce, enquanto que o jus sanguinis é a nacionalidade transmitida pelos progenitores. 
Porém, a eleição de uma categorização de caráter político-estatal que descartava a percepção de certos grupos não obedeceu a critérios de visibilidade numérica - embora esta razão fosse invocada -, já que a população negra e a indígena foram quantitativamente superiores a muitos grupos europeus. Pelo contrário, a adoção desses critérios partiu da afirmação da enorme dificuldade técnica existente para medir a população segundo critérios raciais e da dificuldade, no plano empírico, da distinção segundo critérios étnicos visíveis "de fora". Assim, a diferenciação por nacionalidade, foi tomada como categoria de análise "igualitária e objetiva" que suprimia as categorias do passado colonial, contribuindo para uma apresentação não discriminatória das populações que chegavam e embranquecendo a nação. Porém, o novo paradigma político-estatístico moderno e igualitário resultou contraditório com as considerações ideológicas mais gerais, expresso na avaliação das raças não brancas como inferiores e o "problema" de sua integração. Princípios de 'seleção natural', superioridade regenerativa da raça branca, efeitos positivos e rápidos do crisol de raças eram exaltados como justificativas para as novas categorias em uso, mas sem ter os dados necessários para sua comprovação empírica. $O$ resultado foi o de estabelecer uma autêntica genealogia através da qual o sistema estatístico oficial projetava o futuro de uma determinada imagem da Nação Argentina.

Com essas idéias presentes, pesquisei nos censos seguintes dos anos 1947 e 1960. Em relação ao primeiro, a grande divisória da população total da Argentina era a condição de "nativo" e "estrangeiro" entre as pessoas. Nas páginas introdutórias da publicação do censo de 1947 há um texto que justifica dita divisão: "[...] más del 90 por ciento de la población, hoy en día, es de sangre europea; los nativos com sangre indígena o negra pura, sólo constituyen una ínfima minoría” (INDEC, 1947, p.61).

Em relação aos indígenas, aparecem classificados como "população civilizada” a diferença com os censos anteriores, em que aparecem estimativas da população indígena não incorporada à vida civilizada: "en la actualidad, toda población del país está incorporada a la civilización, pues los núcleos de indígenas hoy existentes, viven plenamente la vida integral de la Nación” (INDEC, 1947, p.28).

Em relação aos negros:

Después de los españoles europeos, el grupo foráneo más importante era el de los negros importados del África como esclavos (...) Interrumpida la importación de esclavos como consecuencia de la declaración de la Asamblea del Año 1813, el número de negros declina rápidamente a causa de la mezcla de sangre com individuos blancos e indios, y por la mayor mortalidad característica de dicha raza. En 1881 se estimaba que su proporción era en Buenos Aires de un 16 a 18 por mil. En la 
actualidad dicha relación debe ser forzosamente muy inferior, no revistiendo, por lo tanto, importancia desde el punto de vista social el grupo de personas de raza negra en nuestro país (INDEC, 1947, p.60).

Note-se que na fabricação dos nacionais, espanhóis europeus e negros são classificados inicialmente como exteriores à nação. E, no caso dos negros, incorporados a nação através da "mescla de sangue", ou seja, preconizando um branqueamento.

Seja no plano do avanço da civilização/cultura sobre os indígenas, seja no desaparecimento racial dos negros, estes deixam de ter expressão como grupos que conformam alteridades. No caso dos imigrantes, na próxima geração, serão argentinos.

Já no censo de 1960, em relação com a origem da população, existe um interesse maior pelas correntes migratórias internas do que pelas migrações internacionais. $\mathrm{O}$ interesse é consolidado na inclusão de uma pergunta específica no censo para as pessoas que declararam como residência habitual um lugar distinto daquele de seu nascimento, perguntando qual o lugar último de moradia e o ano de seu traslado. Podemos entender essa preocupação como uma tendência comum a outros países de mapear os "problemas sociais", no caso aquele monitoreamento estava preocupado com o processo de crescimento urbano das grandes capitais.

Nos censos posteriores de 1970, 1980 e 1991, não aparecem justificativas do uso de categorias de origem da população, sendo normalizada a distinção nacional/estrangeiro. Desta forma, algumas "certezas" sobre a nação e o “nacional” estavam sendo já preestabelecidas.

\section{O Censo Como Arena de Disputas Políticas Atuais}

Em maio de 2003 e em maio de 2004 realizaram-se em Buenos Aires reuniões com as organizações afroargentinas convocadas pelos representantes do BM e do INDEC. Na primeira, que contou com um grande número de organizações afro, delinearam-se os pedidos e as possibilidades de implementação da contabilidade dos afrodescendentes. A segunda reunião foi convocada com uma proposta concreta do BM de encaminhar um fundo para financiar uma prova piloto para testar o instrumento de medição.

Para analisar as negociações realizadas nessas reuniões, usei documentos do BM, publicados no site da instituição ${ }^{8}$, e conversações com ativistas e funcionários do INDEC que participaram desses encontros. A partir dos "entreditos" assinalados, ressalto como os diferentes atores constróem a

\footnotetext{
${ }^{8}$ www.bancomundial.org.
} 
afrodescendência num campo de tensões ocasionadas pela disjunção de lógicas operando na negociação.

Em relação ao BM, em seu papel de mediador para dar visibilidade a um problema social "real" (exclusão / racismo), parte da idéia de que os Estados tem que dar alguma solução. Questão que pode ser relacionada com a preocupação destes atores globais em incluir a variável étnica e racial em seus programas de desenvolvimento, mas estabelecendo uma relação não problematizada entre etnicidade - raça e pobreza, através da elaboração de uma lista pre-estabelecida de "problemas sociais" a buscar nas realidades locais.

Os funcionários do INDEC ressaltam os problemas ‘burocráticos' quanto as dificuldades técnicas do trabalho salientando uma lógica quantitativa. Constróem o problema afrodescendente como uma "minoria não visível" em termos de cor. Esse fato, somado a um frágil auto-reconhecimento da origem étnica, leva a que metodologias quantitativas, dentro de uma lógica do "realismo estatístico" (que busca através das estatísticas uma "realidade" exterior e objetiva sem problematizar seu papel na construção dessa realidade), aponte para a inviabilidade da inclusão de uma pergunta no censo ${ }^{9}$.

Nesses enquadramentos, se tomarmos o parâmetro pre-determinado que vincula "raça”, "origem étnica” e "pobreza" para categorizar aos afroargentinos, corre-se o risco de reforçar a idéia hegemônica de que "verdadeiramente" não existem negros na Argentina, reduzindo a complexidade do problema. Tal situação evade uma outra problemática: a do não reconhecimento oficial da população negra na Argentina, que não necessariamente se inscreveria relacionada a pobreza, mas que se confronta com situações de racismo.

Para os ativistas, além dos dados objetivos que possam ser extraídos dos censos, isto significaria um primeiro passo para que a sociedade civil reconheça sua existência. Nesse sentido, as políticas censitárias tem uma forte dimensão emocional, ligada ao reconhecimento oficial. O censo ano cumpre só uma função de contabilidade, também é um eixo de lutas pela invenção e legitimação de categorias de identidades coletivas.

É precisamente essa dimensão que fica subsumida no discurso dos funcionários do BM e do INDEC e na compreensão de que as classificações são uns terrenos politicamente importantes, que mexem com a fabricação da experiência identitária individual e coletiva.

\footnotetext{
${ }^{9}$ Aliás, a referência que os funcionários têm é a da inclusão da pergunta sobre auto-identificação indígena no censo de 2001 (todos esses funcionários participaram), experiência que trouxe problemas burocráticos no processo de implementação.
} 
Os ativistas participantes do processo de negociação consensuram duas perguntas para testar na Prova Piloto. A primeira, que interroga sobre se há alguma pessoa que seja "afrodescendente", e a segunda, que refere a se alguma pessoa reconhece um ancestral afrodescendente ou africano. Segundo os ativistas, o termo "afrodescendente" foi escolhido para ser parte da pergunta por "sintetizar", em certo modo, as problemáticas com as que se confrontam os líderes. Se bem não é um termo usado amplamente na Argentina, é uma categoria de auto-identificação consensuada na Conferência de Durban. Expressa uma identidade política latino-americana, resignificando o termo de identificação política "negro”, que ainda apresenta vínculos com a história colonial. Privilegia a ascendência por sobre a cor, questão importante para os afroargentinos, que apresentam uma variedade de traços físicos que dificultaria sua identificação por categorias de raça. Nesse sentido, pode incluir brancos que se reconheçam como descendentes de africanos. Aliás, pode incluir não só argentinos, mas também imigrantes negros. Se bem gerou consenso, é necessário ressaltar que também é um termo em disputa.

Vemos que as próprias negociações pelo censo reorganizam as fronteiras da coletividade, pelo menos na visão dos líderes que empreendem esse tipo de pleitos frente ao Estado e em sua tarefa de definir quem conforma e quais são as características da coletividade a qual representam.

Cabe mencionar que durante os anos 80 e 90, o ativismo negro adquiriu certa relevância na Argentina, numa arena pública local marcada por valores de "democratização cultural" e "participação cidadã”. Aliás, nessa época houve importantes fluxos migratórios de população negra de países latinoamericanos e africanos, questão que impulsionou debates públicos sobre o lugar da população negra na Argentina, tanto através de um ativismo relacionado com a reivindicação de uma herança cultural africana no Río de la Plata, quanto uma militância que retomou problemáticas da descolonização africana para refletir sobre a realidade dos negros na Argentina.

Essa arena pública se diversifica a fins dos anos 90, com um processo de ampliação dos espaços políticos dos movimentos negros na América Latina. A "afroargentinidade" e a "afrodescendência" como categorias de auto-identificação expressam uma pluralidade de demandas e a introdução de novos clivagens entre os protagonistas de um amplo espectro de organizações e atividades. Em relação às demandas, criam-se coalizões de ativistas que ressaltam a clivagem entre "nacionais" (afroargentinos) e "estrangeiros" (imigrantes negros recentes), diferenciando o tipo de reivindicação que levam a cabo e como se relacionam com o Estado. No caso dos afroargentinos, as reivindicações dos anos 90 apontavam à dívida histórica do Estado para com os descendentes das pessoas que foram escravizadas nesse território. No caso dos 
imigrantes, as reivindicações apontavam a diáspora africana em geral, tanto histórica quanto atual, relacionada com o processo de escravidão. Seus pleitos estavam mais relacionados com políticas anti-discriminatórias e a defesa de Direitos Humanos em geral.

Essas coalizões dos anos 90 são reformuladas frente a Conferência de Durban. A clivagem principal, que antes referia ao tipo de relação com o Estado (se eram "nacionais" ou "estrangeiros"), passa a diferenciar as organizações que têm fortes conexões transnacionais (quer dizer, apoio internacional para os pleitos locais e inserção nos circuitos de financiamento, que dão certa continuidade nas atividades das organizações), das que ano as têm.

Com as negociações em relação ao censo, as clivagens entre "nacionais" e "estrangeiros" volta a ter força, já que se está debatendo sobre como o Estado classifica à população negra e sobre a identificação de sujeitos de direito, possíveis beneficiários de políticas públicas. Nesse sentido, ressalto que o termo "afrodescendente" foi consensuado entre os ativistas, mas que ocasionou fortes debates em relação a quem incluía.

\section{Considerações finais.}

No trabalho evidenciei o censo como um processo político, construtor da realidade social e não só como reflexo da sociedade; tanto historicamente quanto nas lutas atuais pelas classificações censitárias para o reconhecimento oficial de minorias excluídas.

A construção dominante de uma "branquitude" da nação argentina a partir de processos de invisibilização dos negros da história e cultura nacional foi materializada, entre outros mecanismos, através de operações censitárias. O projeto político baseado no princípio liberal de igualdade perante a lei, apontava a uma homogeneização da população, que privilegiava como elemento formador ao segmento branco, despreciando a negros e indígenas. Os censos de população não foram uns instrumentos passivo ou simplesmente descritivo de medição, já que através da definição e seleção de categorias de análise contribuíram a criar uma imagem da nação que resultou, em parte, autônoma do processo histórico.

Destaquei também que as disputas atuais pelas categorias censitárias formam parte de um espaço político transnacional que articula aos atores globais e as organizações da sociedade civil nas demandas frente aos Estados nacionais para a contabilidade dos afrodescendentes.

A construção do problema do reconhecimento dos afrodescendentes por parte dos atores globais, tais como o BM e o BID, cria imagens de "autenticidade" e "vulnerabilidade" que deixam por fora muitos dos grupos que pretendem incluir. Nesses enquadramentos, se tomarmos o parâmetro 
pre-determinado que vincula "raça”, "origem étnica” e "pobreza” para categorizar aos afroargentinos, corre-se o risco de reforçar a idéia hegemônica de que "verdadeiramente" não existem negros na Argentina, reduzindo a complexidade do problema. Tal situação evade uma outra problemática: a do não reconhecimento oficial da população negra na Argentina, que não necessariamente se inscreveria relacionada à pobreza, mas que se confronta com situações de racismo.

Os agentes do INDEC constróem a problemática afrodescendente referindo a uma "minoria não visível" em termos de cor. Esse fato, somado a um frágil auto-reconhecimento da origem étnica, leva a que metodologias quantitativas, dentro de uma lógica do "realismo estatístico" (que busca através das estatísticas uma "realidade" exterior e objetiva sem problematizar seu papel na construção dessa realidade), aponte para a inviabilidade da inclusão de uma pergunta no censo.

A questão complexa é que, ao associar-se a noção de "pobreza" e de identificação de "problema social" à contabilidade dos afrodescendentes, entrase num debate que choca com imagens consolidadas sobre a sociedade argentina e, portanto, sofre toda sorte de críticas. Entre elas, a da real "utilidade" de quantificar o não-significativo numericamente, frente a outros "problemas" percebidos como mais abrangentes e comuns à pobreza.

Para os ativistas, além dos dados objetivos que possam ser extraídos dos censos, isto significaria um primeiro passo para que a sociedade civil reconheça sua existência. Nesse sentido, as políticas censitárias cumprem não só uma função de contabilidade, também é um eixo de lutas pela invenção e legitimação de categorias de identidades coletivas. "Invenção" no sentido de divulgar publicamente uma categoria "nova" para a sociedade civil, que expressa a existência de afroargentinos e do racismo como problema nacional; e "legitimação" em relação ao próprio grupo minoritário, oficializando uma categoria com a que se auto-denominam e assim, reivindicando sua existência social e sua inclusão nas representações de "nacionais".

Proponho, então, que a constituição de um movimento transnacional negro nos últimos anos está contribuindo para abrir - de maneira particular conforme a conjuntura histórica e política- debates sobre raça e etnicidade na Argentina, mas esses "novos debates" referem a "velhos problemas" sobre como lidar com a alteridade negra num país que reitera um ideário nacional ancorado na "branquitude".

A Constituição de 1994 incluiu direitos vinculados aos povos indígenas e foram ratificados pactos internacionais sobre a eliminação da discriminação racial, que em sua aplicação prática estiveram mais ligados ao anti-semitismo (vinculada com a importância política que ganharam as mobilizações pelos 
atentados contra a Embaixada de Israel e a Asociación Mutual Israelita Argentina na década dos 90). Porém, não houve nenhum dispositivo específico para a população negra. Igualmente, os mecanismos existentes foram usados pelos ativistas afro tanto para canalizar denuncias de racismo quanto para reclamar políticas reparatórias, incluídas as negociações pela inclusão da categoria afrodescendente no censo nacional.

Embora as pressões globais levassem a reformas no marco jurídico do Estado, abrindo a possibilidade das minorias usarem esses novos dispositivos para suas demandas, não chegaram a questionar ideologias dominantes no plano local, o que mostra a difícil implementação de políticas oficiais reparatórias específicas para os afrodescendentes, pensando na branquitude imaginada como predominante, que os coloca como um protagonista que interfere nas certezas produzidas sobre a homogeneidade racial na Argentina.

Por último, considero que uma das contribuições das ciências sociais nessa problemática é a de fornecer ferramentas de análise de complexidade desses processos e campos de disputa, tanto através da desconstrução de discursos dominantes que enquadram as populações minoritárias e recriam desigualdades de poder, quanto de ressaltar a construção de subjetividades nesse contexto: minorias se repensando no meio desses fluxos, redefinindose como comunidades tentando se reposicionar socialmente e no imaginário da nação.

\section{REFERÊNCIAS}

ÁLVAREZ, Sonia; Dagnino, Evelina; ESCOBAR, Arturo (Org.). Cultura e politica nos movimentos sociais latino-americanos. Belo Horizonte: Editora UFMG, 2000.

ARRUTI, José. Direitos étnicos no Brasil e na Colômbia: notas comparativas sobre hibridação, segmentação e mobilização política de índios e negros. Horizontes Antropológicos, Porto Alegre, ano 6, n. 14, p. 93-124, 2000.

GARCÍA, Jesús. Comunidades afro-americanas y transformaciones sociales. In: MATO, D. (Org.). Estudios Latinoamericanos sobre Cultura y Transformaciones Sociales en Tiempos de Globalización. Buenos Aires: CLACSO, 2001.

INDEC. Censo Nacional Argentino. Buenos Aires, 1947.

KERTZER, David; AREL, Dominique (Org.). Census and Identity: the politics of race, ethnicity and language in national censuses. Cambridge: Cambridge University Press, 2002. MATO, Daniel. Actores sociales transnacionales, organizaciones indígenas, antropólogos y otros profesionales en la producción de representaciones de 'cultura y desarrollo. In: . Politicas de identidades y diferencias sociales en tiempos de globalización. Caracas: FACES - Universidad Central de Venezuela, 2003.

OLIVEIRA, João Pacheco de. Cidadania e globalização: povos indígenas e agências multilaterais. Horizontes Antropológicos, Porto Alegre, ano 6, n. 14, p. 125-142, 2000.

OLIVEIRA, João Pacheco de. Entrando e saindo da "mistura": os índios nos censos nacionais. In: . Ensaios de Antropologia Histórica. Rio de Janeiro: Editora UFRJ, 1999. 
OTERO, Hernán. Estadística censal y construcción de la nación. El caso argentino, 1869. 1914. Boletín del Instituto de Historia Argentina y Americana 'Dr. Emilio Ravignani', Buenos Aires, n. 16/17, 1997-1998.

PANTALEÓN, Jorge. Antropologia, desenvolvimento e organizações não-governamentais na América Latina. In: L'ESTOILE, Benoît de; NEIBURG, Federic; SIGAUD, Lygia (Org.). Antropologia, Impérios e Estados Nacionais. Rio de Janeiro: Relume Dumará, 2002. Reid Andrews, George. Los Afroargentinos de Buenos Aires. Buenos Aires: Ediciones de La Flor, 1989.

SMITH, Michael; GUARNIZO, Luis. The Location of Transnacionalism. In: Transnationalism from Below. New Brunswick: Transaction Publishers, 1998. p. 3-34. WADE, Peter. Race and Ethnicity in Latin America. London: Pluto Pres, 1997. WILMER, Frank. The Indigenous Voice in World Politics. Londres: Sage Publications, 1993. 
